the text-books of a hundred years ago. The real- but not admitted-reason why the use of a speculum at an extraction operation was held to be unjustified was because no instrument of the kind had been designed which satisfactorily fulfilled the requirements of the operator or the necessities of the case. Nevertheless, amid all these prevailing disabilities there remained, prominently manifested, the main feature, namely, the dexterity of the surgeon, a high degree of which was indispensable. A skilled operator must have excelled in this faculty in view of the conditions under which he was required to operate. And in the olden days success without it would have been unattainable. Such dexterity also necessarily implied celerity in operating-not a favourable adjunct to an operation demanding such precision and delicacy of movement as that required for an extraction. Has the introduction in our time of anæsthesia, local and general, tended to the maintenance of the supremacy of that faculty, a faculty derived from natural endowment, fortified by continual practice? Have not this quietude, the absence of resistance, the docility of the patient, rather reduced the premium upon its acquisition and lowered the standard of its general application? Without the stimulus of an exacting necessity, progress in an art is apt to decline in one direction or more, while advance is otherwise still maintained. In olden days dexterity was essential as the first step to the success of an extraction ; in these days of cocain, anæsthesia is the first condition to be fulfilled, thus diminishing the urgency of that dexterity to which our forefathers devoted so much successful attention.

\title{
The Vision of Pilots
}

The question of the visual acuity of pilots has been brought into prominence by the recent action of the Marine Board of Victoria, Australia. The tests that have been applied require full vision in each eye, but allow of a deterioration of 30 per cent. in either eye upon re-examination. The Board has considered the advisability of revising this standard, which has been in use since 1914. The pilots, however, have made representations to the Marine Board to have the standard lowered to that of the Board of Trade. The President and the Committee of the Eye and Ear Section of the Victorian Branch of the British Medical Association have issued a protest against the reduction, on the ground that the Board of Trade standard permitted of dangerous defect of vision. This expression of opinion was transmitted to the Elder Brethren of Trinity House, whose reply was unsatisfactory. The latter merely contained a statement of the practice obtaining in London, 
permitting a man with one eye blind and the other with 50 per cent. vision to be in charge of a ship.

[This appears to be an error. The Board of Trade originally accepted the recommendations of the Departmental Committee on Sight Tests, which were that the vision of one eye should be $6 / 6$, and that of the other not less than 6/12. As the result of representations from the trade, the Board of Trade subsequently, on its own responsibility, altered the test to $6 / 6$ with both eyes open; i.e., if one eye has $6 / 6$, the other may be blind. This is the regulation which at present obtains for masters and mates in the mercantile marine. Presumably it also applies to pilots.-ED.]

The Marine Board of Victoria has now to settle the question, and the Chief Secretary will hear the views of a deputation from the Victorian Branch of the British Medical Association. The Med. Jl. of Australia, (April 21,1917) professes to have no doubt as to the result. L. W. Bickle (Med. Jl. of Australia, April 28, 1917, p. 369) protests against tests made except under ordinary working conditions-in other words, under the action of a cycloplegic. He cites the case of a man who had been at sea for some years, and had passed the sight test on three occasions. Wishing to remain in Australia, he applied for work to one of the largest shipping firms, and was referred to the oculist attached to the firm. The pupils were dilated with homatropin, a small amount of hypermetropia was found, and "the eye man turned him down for this." It is of interest to note that the rejected man later passed the Naval examination, and is doing good service on active duty.

\section{The Cinematograph and the Eye}

Now that there is a tendency in some quarters to look upon the cinematograph as a serious means of education, it becomes important to enquire what, if any, effect it has upon eyes exposed to its influence.

The answer is furnished, partly at any rate, by certain authors who have recently written upon the subject. The National Committee for the Prevention of Blindness (New York) has investigated the question, which receives attention in the Second Annual Report of the Committee, published in November, 1916. The conclusions reached by the acting secretary of the committee are published in another part (page 586) of the present issue. Dr. J. Kerr read an important communication dealing with the effect upon the eye of varying degrees of brightness and contrast before the Illuminating Engineering Society, on February 20, 1917, and he touched in the course of his remarks upon the cinematograph theatre. With the probability that use will be 